\title{
GÉNERO Y EMPRENDIMIENTO. Análisis crítico en torno a la subjetividad de emprendedores y em- prendedoras de la Región Metropolitana, Chile
}

\author{
Carmen Gloria GODOY RAMOS*; Manuela RODRÍGUEZ CAREAGA**; An- \\ gélica SANTOS CAULLÁN***; Nicole TAPIA MÉNDEZ**; Gittel VILLABLAN- \\ CA ZARAFF**; Gabriela VILLARREAL DÍAZ**; Soledad ZÚÑIGA VERGARA \\ *Universidad Diego Portales (Chile). ${ }^{* *}$ Universidad Academia de Humanismo Cristiano (Chile) \\ cggodoy82@hotmail.com,mrodricareaga@gmail.com, asantosc86@gmail.com,nicole.tapia.mendez@ \\ gmail.com, g.villablanca.za@gmail.com, gabrielaavd@gmail.com, soledad.zuniga.vergara@gmail.com
}

GENDER AND ENTREPRENEURSHIP: Critical analysis on the subjectivity of women and men entrepreneurs of the Metropolitan Region, Chile

Resumen: El emprendimiento es una actividad económica que en Chile ha adquirido gran importancia y es promovida desde el sector público y privado. Uno de los aspectos que suelen destacarse es que contribuye al desarrollo económico, la innovación y la creatividad "sin distinciones de género", y que resulta especialmente adecuada para las mujeres dado que les permite compatibilizar sus roles productivos y reproductivos. En este trabajo presentamos el análisis de entrevistas semiestructuradas realizadas a hombres y mujeres de la Región Metropolitana de Santiago, entre 21 a 58 años, que se autodefinen como emprendedores. El artículo se desprende de una investigación de carácter cualitativo realizada durante el año 2016 y se enfoca en la subjetividad emprendedora a partir de las experiencias y las ideas que las personas entrevistadas manejan sobre el emprendimiento, y particularmente, en la aparente neutralidad de género que involucra la actividad emprendedora y el sujeto emprendedor.

Abstract: Entrepreneurship is an economic activity that in Chile has acquired great importance and is promoted from the public and private sector. One of the aspects that is often emphasized is that it contributes to economic development, innovation and creativity "without gender distinctions", and that appears especially suitable for women since allowing them to compatibilize their productive and reproductive roles. In this paper, we present the analysis of semi-structured interviews conducted with men and women of the Metropolitan Region, between 21 and 58 years of age, who define themselves as entrepreneurs. The article emerges from a qualitative research carried out during the year 2016 and focuses on the entrepreneurial subjectivity based on the experiences and the ideas of persons interviewed about entrepreneurship, and particularly on the apparent gender neutrality that involves the entrepreneurial activity and being an entrepreneur.

Palabras clave: Género. Emprendedor. Emprendimiento. Neoliberalismo. Subjetividad Emprendedora Gender. Entrepreneur. Entrepreneurship. Neoliberalism. Entrepreneurial Subjectivity 


\section{Introducción ${ }^{1}$}

Este trabajo se propone abordar la experiencia de hombres y mujeres emprendedores de distintas edades, nivel educativo y socioeconómico, y los significados que le otorgan a una actividad que, en Chile, durante la última década, ha adquirido creciente importancia, traduciéndose en la creación de una serie de instrumentos de financiamiento, instancias de capacitación y/o promoción ${ }^{2}$, así como también en un discurso que circula y se replica tanto en los medios de comunicación como en organizaciones públicas y privadas orientadas al tema ${ }^{3}$.

El emprendimiento presenta una variedad de situaciones. De acuerdo con la Cuarta Encuesta de Microemprendimiento, que reúne datos del 2015, el emprendedor corresponde al dueño (o socio) de una unidad económica, esto es, un trabajador independiente que puede ser tanto Empleador como Trabajador por Cuenta Propia, y que, según el número de trabajadores de su unidad económica, puede ser calificado desde microemprendedor a un gran empresario. En Chile existen 1.865.860 microemprendedores, de los cuales 1.112.920 son hombres $(61,3 \%)$ y 702.018 mujeres $(38,7 \%)$ (MINECON, 2016: 1). Los “trabajadores por cuenta propia" corresponden a aquellos "trabajadores y trabajadoras que auto-explotan su fuerza de trabajo" (Brega, 2016), y pueden ser tanto profesionales y agricultores independientes como vendedores callejeros y trabajadores a domicilio principalmente del rubro textil y alimentación ${ }^{4}$.

Pero ¿qué significa ser un emprendedor o emprendedora? Como plantea Richard Pfeilstetter (2011), los conceptos de emprendedor y emprendimiento no tienen un significado preciso, a pesar de la variada producción de artículos académicos, concursos, premios y fomento al desarrollo de iniciativas de apoyo al entorno emprendedor, entre otros, que definen a los emprendedores como agentes de cambio social. Sin embargo, tras estas definiciones el emprendedor se configura como un sujeto moderno, el sujeto ideal para una economía de (libre) mercado, quien, mediante su esfuerzo personal, libre y en igualdad de oportunidades, aporta al desarrollo humano a partir de una forma de vida, "tanto un derivado de ese nuevo sistema flexible como un aprovechamiento activo de sus posibilidades liberadoras" (Op. cit.: 3$)$.

1 Este trabajo se basa en los resultados del proyecto "Trabajo, género y emprendimiento: un análisis crítico en torno a la subjetividad de emprendedores y emprendedoras de la Región Metropolitana", Núcleo Temático de Investigación Cultura, Subjetividad y Política, Escuela de Antropología, Facultad de Ciencias Sociales, Universidad Academia de Humanismo Cristiano, Chile. Investigadora responsable: Carmen Gloria Godoy Ramos. Asistentes de investigación: Manuela Rodríguez, Angélica Santos, Gabriela Villarreal y Soledad Zúñiga. Tesistas de pregrado: Nicole Tapia y Gittel Villablanca.

2 La Corporación de Fomento a la producción (CORFO) ofrece apoyo al emprendimiento en tres categorías: Personas Naturales (que inician proyectos innovadores), Empresas o empresarios individuales ("En formación y que quieran iniciar proyectos de innovación. En crecimiento o consolidados que apoyen a emprendedores") e Intermediarios ("Incubadoras, aceleradoras, redes de mentores, redes de ángeles, coworking, crowdfunding, hub globales y fondos de inversión en etapas tempranas que apoyen a emprendedores"). Ver: https://www.corfo.cl/ sites/cpp/\%20emprendimiento?resolvetemplatefordevice=true.

3 El año 2012 fue declarado Año del Emprendimiento, como actividad que contribuye al desarrollo económico del país, fomentando la innovación y creatividad, "sin distinciones de género". El expresidente Sebastián Piñera Echeñique instauró, el año 2013, el 29 de abril como el Día Nacional del Emprendimiento. Ver: http://pulsosocial.com/2013/04/29/hoy-se-celebra-en-chile-el-primer-dia-nacional-del-emprendimiento/

4 Ver, por ejemplo, entrevista a Francisco Gazmuri, director de la Asociación de Emprendedores de ChileASECH: "Vender sopaipillas en la esquina también es emprender. Me agrede que los lleven presos". La Segunda, 21 de marzo de 2016. También: "Trabajadores por cuenta propia: quiénes son los que soportan el bajo desempleo en Chile", artículo en el que se presenta, entre otros, el testimonio de un migrante peruano que "llegó a trabajar como obrero en la construcción", aburrido de que no le pagaran "decidió cambiar de rubro y autoemplearse vendiendo accesorios para perros sobre un mantel en la calle". En La Segunda, 31 de marzo de 2016. 
El Global Entrepreneurship Monitor (GEM), la entidad más importante dedicada a estudios sobre el tema, desde un enfoque centrado en lo económico, define el emprendimiento o proceso emprendedor como: "Cualquier intento de nuevos negocios o creación de nuevas empresas, la reorganización de un negocio o la expansión de uno existente, por un individuo, grupo de individuos o formas ya establecidas" (Amorós y Pizarro, 2007: 9). Dicho intento requiere de cierta disposición y tolerancia a la inestabilidad, la incertidumbre, el esfuerzo de hacer y hacerse día a día.

Emprender resulta una actividad que puede llegar a concebirse como un proyecto de vida, un compromiso profundo del sujeto consigo mismo, que demanda de un gran esfuerzo físico y psicológico, una tarea a la que "no está dispuesto todo el mundo", dado que incertidumbre y tolerancia al fracaso son dos aspectos que caracterizan la "aventura" de emprender. Teñido de una vocación trascendente -un "llamado"- debe estar en coherencia con las motivaciones más profundas de una persona, de tal modo que la lleve a "apasionarse" por lo que hace. Podemos apreciarlo en las siguientes citas, la primera corresponde a un sitio web dedicado a temas de innovación (un tema estrechamente ligado al emprendimiento), y la segunda a un manual para emprendedores:

"Emprender es una de las cosas más satisfactorias del mundo, y el poder crear y vivir tu sueño y no el de otro es algo absolutamente genial, pero no es para todo el mundo. "Emprender significa vivir en la incertidumbre, noches sin dormir, jornadas maratonianas [sic] de trabajo, es caerse y volverse a levantar. Y por muy mal que suene, es algo a lo que realmente no está dispuesto todo el mundo" (Innovacion.cl).

"Todos podemos emprender, pero no todos estamos llamados a iniciar cualquier tipo de empresa. [...] si vamos a terminar desgastados, más vale que lo hagamos en algo que tenga un profundo sentido en nuestra vida, en algo que nos haga crecer en consistencia con nuestras habilidades, pasiones y anhelos, y a la luz de circunstancias concretas" (Herrera, 2016: 29).

Como plantea Carla Freeman (2014), en un estudio etnográfico sobre emprendedoras caribeñas de clase media, el emprendimiento no solo constituye un vehículo de autoempleo que permite generar ingresos, sino una sutil forma de ser y de experimentar el mundo que vincula las actividades económicas y la producción del "sí mismo", a partir de la porosidad de las fronteras entre lo público y lo privado. Un medio de vida, un estilo de vida y una forma de ser (Op.cit.: 1 y 24).

El emprendimiento conlleva una elección entre la independencia o el trabajo asalariado. Elección que en el marco del "discurso emprendedor" no solo trasciende las ganancias económicas y se vincula con nuevas formas de subjetivación, sino que, además, no adquiere las mismas características en la experiencia de hombres y mujeres. La Cuarta Encuesta de Microemprendimiento muestra que, si bien el 33,7\% del total de los encuestados afirma que "no tener jefe" es uno de los principales beneficios de ser independiente, para las emprendedoras destaca la posibilidad de realizar tareas domésticas y/o cuidado de niños y adultos mayores en el hogar $(39,6 \%)$, mientras que el caso de los emprendedores se menciona mayormente el hecho de "no tener jefe" (36,8\%). Del mismo modo, el 50\% de los negocios que pertenecen a mujeres funcionan al interior de la vivienda, lo que en el caso de los hombres solo alcanza al 16,2\%. (MINECON, 2016: 3).

Considerando lo anterior, en el año 2016 desarrollamos una investigación en la que nos preguntamos sobre los significados que adquiere el trabajo y la figura del/la trabajador/a desde la óptica del emprendimiento; la relación entre las concepciones y roles de género tradicionales y los atributos y actitudes que debe tener un emprendedor; así como la influencia 
de la capacitación y actividades asociadas al emprendimiento en la producción/reproducción de las subjetividades de género. Si bien existen varias investigaciones con enfoque de género sobre microempresa en Chile y en el contexto latinoamericano (Valenzuela, 2005; Valenzuela y Venegas, 2001) así como sobre los factores que obstaculizan o facilitan los emprendimientos liderados por mujeres (Santander, Martínez y Fernández, 2016; Ortiz, Duque y Camargo, 2008; Carosio, 2004), el emprendimiento es un fenómeno en expansión que requiere seguir profundizando en sus implicancias sociales y culturales. En esta línea, y desde una perspectiva crítica, nos interesa abordar la aparente neutralidad de género que involucra la actividad emprendedora y el sujeto emprendedor; avanzando en la comprensión de un fenómeno que involucra a un grupo particular de sujetos -algunos de ellos afiliados a redes de emprendimiento- entre los cuales existen una serie de diferencias (edad, sexo, nivel socioeconómico, nivel educacional, etc.), pero que integran un mismo sistema simbólico y un mismo campo semántico, en último término el sistema socioeconómico capitalista en su fase neoliberal.

\section{Aspectos metodológicos}

El artículo se enmarca en una investigación más amplia de carácter cualitativo (Hernández, Fernández y Baptista, 2003; Canales, 2006), privilegiando el método etnográfico (Guber, 2001) con enfoque de género (Valdivieso, 2009: 30; Bonan y Guzmán, 2007), lo que permite dar cuenta de actividades, actitudes y contenidos que son incorporados de manera diferenciada por hombres y mujeres producto de los roles que desempeñan en el espacio público y privado, así como de la interacción del género con variables como la edad, posición social, el nivel de escolaridad, etc.

La investigación se desarrolló en la Región Metropolitana de Santiago y contempló la realización de 11 entrevistas semiestructuradas a microemprendedores ${ }^{5}$, y a tres informantes clave, que corresponden a las encargadas de programas municipales enfocados en mujer y trabajo, y a la responsable del programa de microemprendimiento de una institución privada orientada a la capacitación de trabajadores. Por otra parte, se hizo una revisión y sistematización de fuentes documentales primarias y secundarias. Paralelamente se realizó observación participante en 7 eventos o instancias ligadas al emprendimiento, entre ellas eventos gastronómicos, conferencias y encuentros de emprendedores ${ }^{6}$. A ello se suma la participación de uno de los miembros del equipo en un curso de emprendedores online, con el objeto de adentrarse en el discurso emprendedor, vivir la experiencia de participar en la plataforma e-learning y poder abordar los conceptos utilizados por quienes se desenvuelven (educando o educándose) en estos círculos?

En este trabajo presentamos el análisis de las entrevistas realizadas a personas que se autodefinen como emprendedores. Se trata de hombres y mujeres entre 21 a 58 años ${ }^{8}$, pro-

\footnotetext{
5 Un microemprendimiento emplea entre 1 a 9 trabajadores (MINECON, 2016. Nota 1)

6 Feria Nam (Festival latinoamericano de gastronomía organizado por la Municipalidad de Santiago, INACAP y el Ministerio de Agricultura); Evento IF Chile Emprendedores Espacio Italia (IF es Fábrica de Ideas, una plataforma de emprendimiento e innovación que cuenta con sedes en Santiago y Valparaíso, entre ellas Espacio Blanco-Recoleta); Cumbre Latinoamericana de Emprendimiento; Encuentro LOCAL (Espacio Blanco-Recoleta); V Cumbre de emprendedores, Asociación de Emprendedores de Chile (ASECH) y Feria Prisma (The Creek Club - El Reloj - Peñaflor). A ello se suma la observación de una clase en INFOCAP (Instituto de Formación y Capacitación Popular) en el marco de la asignatura orientada al desarrollo de proyectos.

7 Curso "Emprendedores con propósito" impartido por IF Chile, la Academia de la Felicidad y la ASECH. El curso está abierto a todo tipo de público -previo pago de una inscripción equivalente a US\$50-, se propone enseñar las etapas para iniciar un emprendimiento " $y$ las herramientas fundamentales para darle forma a ese sueño y volverlo sustentable económicamente”. Más información en: http://www.academiafelicidad.org/ curso-emprendedores-e-learning/

8 Todas las entrevistas se realizaron previa firma de un consentimiento informado que asegura el resguardo de la
} 
fesionales y no profesionales ${ }^{9}$; en su mayoría personas solteras y sin hijos que residen y desarrollan su emprendimiento en distintas comunas de la ciudad de Santiago, mientras que tres de ellos lo hacen en localidades cercanas (Peñaflor y Talagante). En dos casos se trataba de emprendimientos colectivos, por lo que las entrevistas incluyeron dos o más personas. Seis emprendimientos son desarrollados por mujeres, uno por hombres y mujeres y cuatro, exclusivamente por hombres.

El análisis de las entrevistas se organizó en torno a cuatro ejes temáticos: la filosofía del emprendedor (significados y experiencias de la actividad emprendedora); género (oportunidades y atributos); trabajo (significado y relación con emprendimiento), redes de emprendedores y familia (importancia e influencia en el desarrollo del emprendimiento), y las capacitaciones (conocimientos adquiridos).

El artículo se enfoca en la subjetividad emprendedora y se organiza en tres secciones. En la primera abordamos los conceptos de emprendedor y emprendimiento en el contexto neoliberal, en la segunda, nos centramos en los significados de la experiencia emprendedora a partir de las ideas que los entrevistados y entrevistadas manejan sobre el emprendimiento y la dimensión de género en la experiencia emprendedora. En la tercera parte realizamos algunas reflexiones finales-

\section{El concepto de emprendedor}

Los orígenes del concepto "emprendedor" no se encuentran necesariamente en el terreno económico, fue utilizado en Francia por primera vez en el siglo XVI, bajo el vocablo "entrepreneur" (que significa simplemente empresario y específicamente "contratista" con arreglo a "pionero"); en el siglo XVIII la definición en español refiere a la personalidad de quien emprende, "la naturaleza de la acción y la estrategia utilizada" (CORFO, 2014: 21). En el siglo XIX este "empresario" empieza a ser considerado como un agente económico, y con los planteamientos de Joseph Schumpeter, en las primeras décadas del siglo XX, el término queda vinculado a la idea de innovación, como la "fuerza que impulsa el crecimiento económico [...] un recurso necesario para producir riqueza" (Op.cit: 22). De acuerdo con Pfeilstetter, en la visión de Schumpeter el emprendedor se distingue de las otras personas fundamentalmente por ser un "hombre de la acción". No por el carácter de sus ideas o de la institución que ha creado. La conceptualización de Schumpeter sería mucho "más abstracta y generalista", más cercana al sentido común respecto al término en la actualidad y se expresa en definiciones como las del Diccionario de la Real Academia Española que define al emprendedor como aquel que "emprende con resolución acciones dificultosas o azarosas", y a la acción de emprender como "acometer y comenzar una obra, un negocio, un empeño, especialmente si encierran dificultad o peligro" (Pfeilstetter, 2011: 8).

Es en la década de los 1980 en que el concepto resurge, específicamente con la publicación Innovation and Entrepreneurship: Practice and Principles de Peter F. Druker (1985), considerado uno de los principales filósofos de la administración de empresas. El enfoque de Schumpeter y Drucker presenta la innovación como la principal responsabilidad del empresario, lo que genera la necesidad de un manejo adecuado de la ciencia y la tecnología para crear productos y procesos nuevos y perfeccionados, así como "la búsqueda conscien-

identidad de los y las entrevistadas; para efectos de las citas utilizadas en este trabajo indicamos el sexo del/los entrevistado/s, la edad, estado civil y/o situación de pareja, hijos, profesional o no profesional.

$9 \mathrm{La}$ distinción profesional/no profesional hace referencia a dos grandes grupos en relación a su nivel socio económico y/o cultural: 1) personas que cuentan con título profesional -pertenecientes a las capas media y alta- que abandonan un trabajo asalariado y deciden emprender un negocio de manera independiente; 2) grupo corresponde a emprendedores de capas sociales más empobrecidas, beneficiarios de programas públicos y que, por lo general, requieren acceder a préstamos para impulsar su negocio. 
te de nuevas oportunidades que aumenten el potencial económico y social de la empresa" (Carosio, 2004: 86).

En la actualidad el concepto además de: a) asociarse a la capacidad de incrementar las utilidades de un negocio, b) centrar las energías transformadoras en los sujetos y c) vincularse a la innovación, como ha sido definido históricamente, también se asocia a la resiliencia, bajo el entendido que hoy los emprendedores muchas veces se enfrentan a contextos de crisis económicas, y que son justamente ellas o ellos los que, con sus cualidades emprendedoras, pueden superarlas (CORFO: 22-23).

\section{Neoliberalismo y la "forma empresa"}

De acuerdo con Michel Foucault (2007), los pensadores neoliberales -particularmente en su versión norteamericana- conciben la sociedad bajo criterios mercantiles, sometida a la "dinámica competitiva" más que al intercambio de mercancías, de tal modo que esta se configura como "sociedad empresa". La generalización de la "forma empresa", supone hacer del modelo económico (oferta y demanda, inversión, costo y beneficio) "un modelo de las relaciones sociales, un modelo de la existencia misma, una forma de relación del individuo consigo mismo, con el tiempo, con su entorno, el futuro, el grupo, la familia" (Op.cit.: 278). Así, a diferencia de la concepción económica clásica del homo oeconomicus -como modelo de comportamiento humano-, en que este constituía un "socio del intercambio", en el neoliberalismo este resulta un "empresario de sí mismo [...] su propio capital, su propio productor, las fuentes de [sus ingresos] (Idem: 265).

Un modelo, cabe agregar, masculino. Según Julie A. Nelson (1995), el "hombre económico" históricamente ha sido concebido como un ser independiente, con preferencias claras, activo, autónomo, que interactúa a través de un mercado ideal en que los precios formarían el único medio de comunicación. Pero, así como el homo oeconomicus no describe a la mujer, "tampoco es una buena descripción del hombre", autonomía, racionalidad y objetividad, como equivalente a lo masculino, y dependencia, emocionalidad y conexión como proyección femenina constituyen una falsedad y distorsión (Op.cit.: 6). No obstante, cobra sentido cuando se hace referencia a las "emprendedoras" o en el diseño de programas para "mujeres y emprendimiento", en que se realza su orientación al género femenino como un acento, una marca; una característica por "activar" que debe ser enseñada e incorporada, pero que, además, se debe "conciliar" con los roles reproductivos.

El "self emprendedor", dice Ulrich Bröckling (2015), desciende del homo oeconomicus. El "self emprendedor" opera como una exigencia, una demanda social y un ideal en el marco de la "economización de lo social", que no refiere a una entidad empírica observable "sino al modo en que los individuos son interpelados como personas y, a la vez, la dirección en que son modificados y deben modificarse" (Op.cit.: 61). Un régimen de subjetivación que requiere de la adquisición de ciertas competencias y habilidades, las cuales pueden ser desarrolladas por personas de distintas edades y nivel educativo ${ }^{10}$.

Para Bröckling el contexto político-social y las transformaciones del mundo del trabajo (dado el creciente aumento de trabajadores por cuenta propia o freelancers) han posibilitado la emergencia del self emprendedor como un empresario de su fuerza de trabajo, caracterizado por la tendencia al autocontrol, autoeconomización y auto-racionalización. En este

\footnotetext{
10 Ver, por ejemplo, los Programas de Apoyo al Entorno Emprendedor (PAE) instrumentos de financiamiento que buscan "mejorar las condiciones de entorno en que se desarrollan las actividades emprendedoras en el país". Apoyando iniciativas orientadas a personas y/o empresas, que buscan "validar la opción de emprender, generar espacios y redes, globalizar el emprendimiento nacional, difundir herramientas para la formación de emprendedores, entre otras". (CORFO, 2012:3) En el caso de la investigación citada, se busca aportar "la cultura del sistema educacional chileno, así como otorgar información de alto valor para el diseño de programas de fomento al emprendimiento escolar en Chile".
} 
contexto, la búsqueda de la felicidad individual se orienta a la esfera del consumo, pero hacia un consumo que no promete la satisfacción de necesidades "normadas en el marco de la cultura de masas fordista" sino de aventuras y autorrealización, en un marco en el que las desigualdades de carácter material desaparecen bajo la exaltación de las diferencias (que pueden coexistir como nichos de mercado). De ese modo, el imperativo consumista y empresarial quedan ligados entre sí: "como consumidor, el individuo debía acumular su capital de goce y también debía comportarse innovador, dispuesto al riesgo y decidido como si tuviese que llevar una empresa al éxito mercantil" (Idem: 66).

\section{Análisis. La filosofía del emprendedor y la experiencia emprendedora ${ }^{11}$}

\section{Libertad y creatividad}

El emprendimiento y la experiencia emprendedora adquieren diversos matices de acuerdo con la trayectoria de cada uno de los entrevistados. En algunos de los relatos, aparece como una actividad que han realizado incluso antes que recibiera esa denominación -propia de "emprendedores por naturaleza"-, así como una alternativa para enfrentar el desempleo o bajos ingresos. No obstante, lo disímil de las trayectorias, el emprendimiento se presenta como una experiencia que trasciende lo meramente económico, así como el ser emprendedor supone poner "sangre, sudor y lágrimas" en función de un proyecto que permite conseguir la felicidad y/o la plenitud. Algo que el trabajo dependiente, asalariado u otras formas convencionales de ganarse la vida no permitirían imaginar.

En ese contexto, aparecen dos conceptos clave que podríamos decir que marcan la "narrativa del emprendedor": la libertad y la creatividad. Libertad para disponer del tiempo y para generar un espacio propio dónde trabajar, una suerte de hábitat que permita conciliar intereses, habilidades, conocimientos y, sobre todo, realizar y realizarse en un proyecto que podría asimilarse a vivir la propia vida con total coherencia. Cumpliendo los "sueños propios", no "los de otros". Supone también algo más profundo ya que la acción de emprender y el despliegue de energía para concretar cualquier proyecto, por pequeño que sea, ha de provocar un cambio en sí mismo y en los otros. La búsqueda de la autenticidad y en último término, la búsqueda de la felicidad.

Este el caso de un profesional del área del diseño que luego de siete años como director de arte en agencias de publicidad inicia su propia agencia, la que luego abandona para "autojubilarse" y crear un emprendimiento dedicado a la gestión de Responsabilidad Social Empresarial (RSE). Señala que su emprendimiento le genera una sensación de libertad para poner sus talentos, su creatividad y sus ideas en función de un producto que "puede repercutir en la gente de forma positiva", esto es, la gestión de la creatividad y la creación de ideas en acciones con sentido social (E1, 33 años, profesional, soltero, sin hijos).

Bröckling advierte que la investigación sobre la creatividad fue desarrollada en Estados Unidos después de la Segunda Guerra Mundial, como reacción a "los test de inteligencia que no abordaban la capacidad individual e innovadora para la solución de problemas" y resultaban inadecuados para reconocer tempranamente talentos científicos o high potentials (168). Así, la creatividad aparece como un elemento que debe ser movilizado y liberado, a la vez que requiere de regulación (Op.cit.: 163). Es aquello que distingue a un emprendimiento de cualquier otro tipo de iniciativa. Gestionar la creatividad es la forma de que lo viejo devenga en algo nuevo, y lo innovador se convierte en una cualidad otorgada por terceros.

La creatividad es considerada como una capacidad que todo ser humano posee, "el estado natural de las personas", pero para efectos del emprendedor el problema a resolver es el de la innovación y el éxito, cómo conseguir imponerse a la competencia, porque "no solo se requiere de un espíritu inventivo pragmático, sino también de fantasía artística, trabajo

11 Cada entrevista ha sido identificada con un número: E1, E2, etc. 
duro, deseo destructivo subversivo, vitalidad desatada y lideresa en el juego" (Ídem: 168). En el caso mencionado la creatividad también entrega una satisfacción:

“[...] Hoy día algo que a mí me genera mucho placer, satisfacción y todo es vivir de mis ideas [...] y aportar un granito de arena a ese tipo de ideas a mí me hace dormir tranquilo, estar contento, me genera mucha endorfina en mi cabeza, la endorfina hace que las ideas se potencien, y así es una cadena virtuosa [...] Yo ando como ahora con papel y lápiz siempre, viendo situaciones, anotándolas, que yo le llamo insight, son ideas ocultas y que se levantan, verdades ocultas que están, pero no siempre se ven. Y eso me genera mucha satisfacción, en eso ando todo el día" (E1, 33 años, profesional, soltero, sin hijos).

Lo que el entrevistado llama insight es un concepto aprendido ${ }^{12}$, y es la fuente que alimenta su imaginación para constantemente crear cosas nuevas. A lo largo de su relato es posible encontrar tips que impulsan la creatividad: ejemplos motivacionales, su experiencia de vida como emprendedor, ejemplo de emprendedores exitosos, metodologías de solución de problemas a partir de la creatividad.

Luego, tenemos el relato de una mujer con estudios universitarios en el área de humanidades que se ha orientado a la venta de productos orgánicos junto con impulsar la creación de ferias de emprendedores en Peñaflor -localidad de carácter rural-urbano cercana a Santiago- donde reside. A diferencia del caso anterior, la creatividad aparece asociada a la experiencia del postnatal y al "tiempo vacío" en la casa:

[Si no hubiese emprendido] "probablemente hubiese hecho otra cosa, cualquier otra cosa, porque estaba en un momento [postnatal] en el que necesitaba hacer algo, algo creativo, [...] sentía que no había nada más que hacer [...] yo necesito algo más, no puedo mantener mi cerebro sólo como dueña de casa, me frustra, me deprime, ya sea leer un libro, pero necesito hacer cosas diferentes" (E2, 29 años, profesional, casada, 2 hijos).

Creatividad implica libertad, gestionar el tiempo para orientarlo al contacto con nuevas personas y lugares. Hacer lo que "a uno le gusta". Todo ello se opone a la rutina, el trabajo dependiente, los horarios, las jerarquías. Del mismo modo, el emprendimiento se transforma en la concreción de un "sueño", de una idea que independiente que sea exitosa o no, se expresa en el "mundo físico" lo que constituye en sí mismo una satisfacción.

Pero la creatividad también es gatillada por la angustia y la desesperación: la necesidad de subsistir o en el mejor de los casos, encontrar la solución a un problema. Toda situación de comodidad (la zona de confort) no permite generar ideas nuevas. Esta es la visión de un hombre, diseñador de profesión, que se ha orientado a la formación de emprendedores con acento en la innovación, tanto a nivel universitario -donde se desempeña como profesor de varias carreras-, como en programas de emprendimiento gestionados por instituciones públicas y privadas. Su propia experiencia está marcada por el "trabajo independiente", antes de que recibiera la denominación de emprendimiento:

"[...] hay mucha gente que no está dispuesta a eso [dejar el trabajo], que prefiere la zona de confort de que me paguen el sueldo y ya, pero mírales la cara, tengo todos estos casos, los veo todos los días, todo el día, que se quejan de esto y de la cuestión pero teniendo oportunidades no lo hacen, porque se tienen que hacer cargo, y hacerse responsable es heavy, toda la gente quiere ser 
libre, pero la libertad tiene una responsabilidad y nadie quiere ser responsable [...]" (E3, 50 años, profesional, casado, 2 hijos).

La responsabilidad que conlleva ser libre apunta aquí a tomar el riesgo, aventurarse, y reconocer que las oportunidades "están ahí". Sin embargo, esta visión contrasta con la experiencia de una profesora de arte que dejó su trabajo en un colegio no tanto en búsqueda de su proyecto propio, sino por las largas distancias y las dificultades que encontraba para ejercerlo. Su experiencia, como dueña de una pequeña fábrica de ropa, no ha sido fuente de satisfacción sino de angustia y soledad:

“[...] me he sentido muy sola [...] porque a mí, por ejemplo, el sistema me escupió, quedé fuera del sistema y como que todo el mundo sabe que los microempresarios en algún minuto quedan así, porque esto pasa y quedai fuera, pero quién te dice que cuando ya no tení crédito en ningún lado cómo hacerlo, entonces cuando estai sufriendo te dice, "no es que a los microempresarios les pasa esto" pero la angustia el no poder dormir, el no poder pagar tus deudas, el no poder pagarle a la gente que trabaja contigo, no, es muy desagradable [...]" (E4, Mujer, 58 años, profesional, soltera, 1 hijo).

En este caso, se invierte el carácter positivo que se le atribuye a la incertidumbre, el riesgo y la responsabilidad de hacerse cargo de la independencia laboral y pesa una mirada un poco más pesimista respecto a las reales posibilidades de pasar de un nivel de subsistencia a uno donde se potencie la creatividad.

\section{¿Por qué emprender?}

De acuerdo con la definición que dan los mismos entrevistados, existen emprendedores por "necesidad" y por "naturaleza". Los primeros lo harían por necesidad económica, por la contingencia, y los segundos, por una suerte de disposición personal ya que siempre están en búsqueda de nuevas oportunidades.

Una emprendedora exitosa en el ámbito de la tecnología se decidió a emprender pese a tener un empleo que le entregaba estabilidad económica, nuevos desafíos y reconocimiento. La escasez de tiempo, la carga laboral y el colapso ante las responsabilidades de su cargo, son la explicación del porqué deja su trabajo, además de la posibilidad de tener algo propio: "pero yo veía que soy joven, no tengo hijos, la idea me apasionaba por completo, y el tema social yo encuentro que es lo mío, las ganas de tener algo propio también estaban ahí” (E5, 33 años, profesional, casada, sin hijos).

La pasión por iniciar algo nuevo y propio -aun cuando había tomado ciertos resguardos económicos- la empuja a emprender. La necesidad interior de transformar el entorno, lo cual resulta coherente y debe serlo, con su interés por temas sociales.

"[...] entonces me llaman como mentora para trabajar con los chicos que están partiendo y al final fue uno de los aprendizajes que dije en una charla que di el otro día, porque me pidieron hablar a mi como emprendedora, y yo partí diciendo "Yo ¿emprendedora?", porque de verdad cuando lo veía a la gente que partía de cero, a mí nunca se me va a ocurrir esa idea del millón de dólares [...] Pero después me di cuenta de que yo había sido súper emprendedora desde mis espacios de trabajo, porque partí muchas cosas de cero [...]" (E5, 33 años, profesional, casada, sin hijos). 
Sin embargo, también emerge una tensión entre "necesidad" y "naturaleza". Es el caso de una de las entrevistadas, citado más arriba, que luego del postnatal de su segundo hijo inició su emprendimiento. Compró los productos, y mientras llegaba el pedido ideó y organizó junto con más vendedoras/es una feria de productos orgánicos. La feria nació con la idea de impulsar a pequeños productores de la zona y acercar a la gente de la comuna a los productos orgánicos, la alimentación saludable, etc. Si bien en su relato destaca varias veces que no podía "estar en la casa" y que es una persona inquieta por naturaleza, advierte que el boom del emprendimiento que se vive hoy en Chile obedece más bien a la precariedad laboral, porque "al final para ganar el mínimo preferí ganártelo en cuatro fines de semana que es lo que trabajai”, además de buscar a través de esa gestión del tiempo una mejor calidad de vida.

No obstante, esa búsqueda y esa posibilidad de administrar el tiempo a través de un emprendimiento conlleva incertidumbre, frustración e inestabilidad económica, argumentos de peso al momento de considerar iniciar uno o continuarlo. Opinión similar es la una mujer que considera que, si bien el rol de los emprendedores es importante para la economía se enfrentan a una situación de precariedad y vulnerabilidad que permite pocos casos "exitosos":

“[...] estamos como solos, yo creo que somos una pieza como, una pieza clave dentro de la economía del país, pero que somos como la carne de cañón, cachai [...] yo me he encontrado con miles de microempresarios que apenas se ganan las lucas, $[. .$.$] que no tienen un sistema de salud, que no tienen, que si te enfermas,$ nadie, nadie te va a ayudar, excepto la familia o los conocidos, entonces yo la verdad que eso de ser microempresario, de ser como emprendedor, o empresario, es como súper incierto, sacrificado que son como, claro hay gente que le va bien, pero yo creo que son una minoría. Yo creo que el $90 \%$ de los micro empresarios nos damos vuelta nomas" (E4, Mujer, 58 años, profesional, soltera, 1 hijo).

El estado de "necesidad" actúa como un resorte, el impulso que acompaña a quienes no tienen la vida resuelta. Para otro de los entrevistados (un "emprendedor por naturaleza") cuyo relato citábamos más arriba, las personas que emprenden no pertenecen a las clases más acomodadas, sino a las clases medias emergentes cuyo potencial para emprender es mayor, debido a las carencias económicas y a que acompañaron a sus padres en "historias de esfuerzo".

En este sentido, pedimos a los entrevistados que establecieran diferencias entre emprendedores, comerciantes y empresarios. Los dos últimos fueron calificados como sujetos interesados en la ganancia económica: uno solo quiere salvar el día (el comerciante), y el otro solo busca ganar dinero (el empresario). Mientras que el emprendedor, si bien también busca generar ingresos, lo hace desde una concepción distinta en donde debe conciliar sus ideas, expectativas, proyecciones y ambiciones con la venta de un producto o servicio. De ahí la importancia del conocimiento de sí mismo, de los límites y posibilidades, porque un emprendedor se implica a sí mismo en su proyecto. Podríamos decir que se pone en juego a sí mismo/a y el emprendimiento resulta parte de su "crecimiento personal" o de su afán por mejorar el entorno social, no obstante, en la práctica el éxito -y la viabilidad de los proyectos- se mide en términos económicos.

Luego, es tal la conexión entre el emprendedor y el emprendimiento que los mismos argumentos que son utilizados para dejar un trabajo dependiente se aplican al emprendimiento: falta de tiempo, sobrecarga laboral y nuevas responsabilidades. Carla Freeman advierte que la "flexibilidad" que ofrece el emprendimiento se articula como un medio para lograr convertirse en "el propio jefe", controlando no sólo las horas y las condiciones laborales, así como otras dimensiones estructurales del trabajo, sino también los sentimientos sobre el tra- 
bajo mismo, el reflejo del yo, como un medio para actualizar y materializar la personalidad del emprendedor. En los casos que ella analiza, que corresponden a mujeres, observa que en tanto emprendedoras y trabajadoras, estas se someten a condiciones de explotación por el exceso de trabajo, ya que no solo es su empresa, sino que ellas mismas las que siempre están trabajando para producir (Freeman, 2014: 210). Entonces podríamos relativizar el concepto de flexibilidad o considerarla ilusoria, en tanto el emprendimiento exige finalmente una dedicación horaria total, sin tiempos ni espacios diferenciados entre el ocio y el trabajo, sobre todo cuando se desarrolla dentro del lugar de residencia.

\section{El fracaso y el éxito en el emprendimiento}

Tal como se plantea en el "discurso emprendedor" que podemos encontrar en los contenidos de cursos, manuales, y charlas motivacionales, el emprendimiento supone éxitos y fracasos, que un emprendedor debe ser capaz de superar. En ese sentido, una de las actividades a las que asistimos, la Cumbre Latinoamericana del Emprendimiento, contaba con la charla magistral de una suerte de gurú de los negocios y del emprendimiento, Robert Kiyosaki, norteamericano ${ }^{13}$, además de la presentación de tres emprendedores locales ${ }^{14}$. En todas las presentaciones ${ }^{15}$ se reiteraba que el fracaso es parte de la experiencia emprendedora. Prácticamente inevitable, porque "no se puede emprender para ser exitoso"; fracasar es el aprendizaje y la ruta para llegar al éxito. Pero los expositores ya habían superado el fracaso.

Llama la atención, cómo la mayoría de los entrevistados han incorporado este discurso. Aun sin haber asistido a capacitaciones sobre el tema, el fracaso se elabora de manera similar, si bien se agrega una situación intermedia que es la falla o el error.

"Fracasar es que [...] quedaste acostado en el piso y quejándote. Fallar significa que te caíste en la misma magnitud, te sacaste la cresta, te paraste, te lavaste las rodillas y la cara, seguiste. Nadie se levanta un día en la mañana y le va bien para siempre. Tú te levantas en la mañana, empiezas un emprendimiento y empiezas el viaje y pasas por mil peajes, y cada peaje es una falla [...] es un aprendizaje" (E1, 33 años, profesional, soltero sin hijos).

De este modo, fallar es levantarse y seguir, fracasar es rendirse y no continuar el viaje. Pero esto también puede ser elaborado de manera más pragmática. Una de las entrevistadas, dice que el éxito depende de tener una visión clara sobre lo que se quiere, lo que se traduciría en una buena organización o planificación que le permitiría tener un bienestar económico como si fuera una trabajadora dependiente:

“[...] no soy una emprendedora exitosa, soy una emprendedora que se ha logrado mantener en el tiempo, pero no soy exitosa, exitosa yo diría que estés muy bien organizada, que te permita ganar lo suficiente como para tener salud, vacaciones, yo a eso le llamaría como, lo que todos tienen la gente que trabaja

13 El libro es Padre Rico, Padre Pobre (1997), donde aboga por la libertad financiera y la educación financiera en las escuelas. Respecto a la distinción entre el "padre rico" y "padre pobre", que también desarrolló en la conferencia, en una entrevista señala: "Si miras a Grecia hoy, está en quiebra. España, está en quiebra. Italia, Venezuela, Brasil, Estados Unidos", enumera. "Todos ellos están dirigidos por gente con formación académica, como padre pobre; pero no con educación financiera, la del padre rico" (Soteras, 2017).

14 Aunque no lo desarrollamos aquí, cabe también analizar el desplazamiento y la forma de ocupar el escenario de los expositores, incluso la gestualidad desplegada, sobre todo de quienes se presentan como emprendedores exitosos.

15 Entre ellas la de Ricardo Guital, una de las figuras chilenas más citadas en los casos de emprendimientos exitosos y miembro del directorio de la ASECH. Ver los detalles de su descripción en la página de la asociación: https://www.asech.cl/nosotros/directorio/ 
como con un sueldo y contrato, esa estabilidad, que bueno, tampoco es tan estable" (E4, 58 años, profesional, soltera, 1 hijo).

Pero los costos de las caídas se pueden manejar mejor si se tiene conocimiento de sí mismo/a. Dado que emprender es una acción que involucra un riesgo, el emprendedor no puede temer al fracaso. En ese sentido, se debe tener fe, no necesariamente una fe religiosa, sino una actitud positiva, entender que "todo pasa por algo". Por tanto, es necesario "fortaleza espiritual” porque el emprendedor no está en una posición cómoda:

“[...] el emprendedor puede hacer un montón de cosas si no le resultó una, hace la otra, hace la otra, el espíritu emprendedor no toda la gente lo tiene, porque es muy cómodo poder trabajar en una empresa y que lo manden y hacer lo que otras personas quieren que haga, el emprendedor, él tiene que tomar la decisión, él tiene que equivocarse, él tiene que apechugar con todo lo que tiene a su disposición entonces cada logro uno lo valora más porque lo hizo uno a la pinta de uno y si resultó, qué bueno" (E6, Mujer, 58 años, no profesional, soltera en pareja, dos hijos).

Del mismo modo, un fracaso es la oportunidad de reinventarse e iniciar de nuevo el camino, como señalan las creadoras de una productora de contenidos:

"Emprender es hacer lo que te gusta, lo que deseas hacer, disfrutar el trabajo, que genera redes y ayuda a otros a emprender, es ser perseverante frente al fracaso, es arriesgarse, ser valiente, es independizarse para ser tu propio dueño. Se debe tener fe para superar los fracasos. Superando los fracasos se logra el éxito" (E7, 30 años, profesionales, casada y soltera, sin hijos) .

\section{La dimensión de género: atributos y actitudes}

Respecto al género y al sexo de quien emprende la opinión compartida, en general, es que estos no serían impedimentos: tanto hombres como mujeres pueden llegar a convertirse en emprendedores exitosos. Sobre todo, cuando permite que las mujeres consigan "la emancipación financiera" sin descuidar las tareas reproductivas, pero también, aumentar los ingresos que obtienen a como "dependientes" a través de un emprendimiento:

“[...] éramos más mujeres que hombres en la feria orgánica, muchas, muchas mujeres, [...] puede ser que sea una coincidencia del destino, como puede ser que las mujeres en etapa fértil, con guagua, siempre estamos buscando la forma de estar más tiempo con nuestros hijos, siempre, y la verdad es que desarrollar un trabajo en casa claro que te da tiempo para estar con tus hijos y te da la posibilidad de organizar tus tiempos, por último los llevas un rato al jardín infantil y puedes hacer tu negocio, y después estás gran parte del día con ellos, pero también está esta cosa, por ejemplo, es la precariedad del trabajo, muchas mujeres trabajan de lunes a viernes y los fines de semana buscaban esto" (E2, 29 años, profesional, casada, 2 hijos).

Esto concuerda con el discurso que promueve el emprendimiento como una actividad apropiada para mujeres de diversos sectores sociales en la medida que permite la generación de ingresos propios y la compatibilización de sus roles productivos y reproductivos (Godoy, 2016: 872-873). Así, el impulso a la autonomía económica de las mujeres como forma de superación de la pobreza es un tema sobre el cual existe consenso entre distintos sectores 
políticos -aunque con distinto contenido ideológico- y, en este sentido, se releva la importancia de eliminar los obstáculos que impiden su plena incorporación al mercado laboral (Op.cit.: 252). Pero la motivación económica que conlleva esta actividad muchas veces está más ligada a la subsistencia, una actividad que genere un ingreso mientras se encuentra una nueva oportunidad de empleo estable.

"[...] el hacer clases fue una experiencia como un poco triste para mí, me gustaba mucho hacer clases, [...] no se me dieron las oportunidades, bueno en los [años] 84-85 era muy, muy poca las posibilidades que tuve de hacer clases y siempre fue en colegios como súper lejos de donde yo vivía, tuve malas experiencias porque no me pagaban, porque los colegios se cerraban [...] no dije ¡oh, voy a ser una microempresaria! empecé, como te decía mientras esperaba una oportunidad de hacer clases, empecé a trabajar en la casa, a aprender a hacer cosas, mi mamá me enseñó a diseñar y ahí partí, fui autodidacta en esta área". (E4, 58 años, profesional, soltera, 1 hijo).

Como ya dijimos, entre las entrevistadas predomina la visión de que no hay obstáculos ni privilegios relativos al género. De hecho, "el género no tiene nada que ver con el emprendimiento":

“[...] porque no es una cuestión de género, es una cosa de personalidad y de perspectiva, como te digo, una persona que lo intenta una vez y que dice, esto no me resultó y chao, no es un emprendedor. Porque es parte de la personalidad de cada uno, no hay género en esto, no siento que lo haya" (E2, 29 años, profesional, casada, 2 hijos).

Sin embargo, cuando se trata de caracterizar los atributos y actitudes de hombres y mujeres en el ámbito del emprendimiento, estos se corresponden a las visiones más tradicionales sobre lo masculino y femenino y los roles de género. De modo tal que los hombres emprenden por intereses propios, mientras las mujeres lo hacen por su familia:

"[...] siento que muchas veces los hombres se mueven en el plano egocentrista, es como su negocio, y es para ellos, la ganancia va a ser para ellos, por ellos, todo por ellos, siento que la necesidad de emprender de un hombre es por satisfacer una necesidad de ego muchas veces, o porque tienen una buena idea y saben que va a funcionar, cachai, en cambio siento que la mujer tiene que ver con la familia, no con llenar una expectativa, "ah, esta mina va lograr algo", no, no es eso, siento que es algo como, quiero darle algo mejor a mi familia" (E2, 29 años, profesional, casada, 2 hijos).

En otro caso, al mismo tiempo que el entrevistado reconoce que las mujeres se posicionan cada vez más como emprendedoras, al profundizar en este aspecto lo hace a partir de atributos y capacidades que han sido naturalizados como propios de cada género. Los roles familiares y las tareas de cuidado que las mujeres han desarrollado históricamente se proyectan a lo público como la búsqueda del beneficio colectivo. En este sentido, cuando se refiere a una mujer muy reconocida en organizaciones de emprendedores, enfatiza su papel en la asociatividad estableciendo una analogía con la familia y los roles de las mujeres:

"[...] la postura de ella es decir "reunamos a todos en un lugar, porque mientras más seamos, más nos fortalecemos", eso es propio de una mujer desde mi punto de vista... o sea en mi casa y lo más probable que en la tuya y la de 
muchos otros, la abuela es la que reúne a la familia, la abuela es la que dice 'ya, me paran el hueveo todos y se me juntan a almorzar aquí el domingo, nos reunimos aquí, y así tiene que ser. El concepto familia, el hombre: no, me da lo mismo, hagamos un asado, que lleguen los que lleguen" (E1, 33 años, profesional, soltero sin hijos).

De este modo, frente al "egoísmo" masculino las mujeres ofrecen el bien común; mientras los hombres compiten, la mujer- madre cuida a la prole y en Chile, destaca un entrevistado, incluso a los padres. Por otro lado, y contradiciendo a la visión igualitaria del emprendimiento, la capacidad de tomar el riesgo y enfrentar las adversidades adquiere un matiz masculino:

"Tienes que creer que las cosas son posibles, no puedes ser un gallo victimizado, no llegas ni a la esquina, hay que ser un macho: "oye tú no puedes", hay que soñar, tienes que pensar que es posible" (E2, 50 años, profesional, casado, 2 hijos).

"[la mujer] no se arriesga, es más asegurada, no le nace o no tienen la fuerza para decir, si poh yo lo puedo hacer, cachai, el hombre lo puede hacer porque es más atarantado, ¿se entiende? pero no digo que las mujeres no lo pueden hacer y es bacán ver buenos emprendimientos de mujeres y de hombres también, [...] pero pensando en el universo de gente que tengo alrededor [...] que podría llamarse emprendedora de lo que hemos ha" (E8, 21 años, estudios universitarios, soltero, sin hijos).

Desde esa perspectiva, la acción emprendedora se visualiza como masculina, dentro de los modelos tradicionales de género que atribuyen sobre todo el riesgo -y cierto grado de irresponsabilidad o falta de precaución- a la conducta propiamente masculina. Como portadoras de ciertos atributos las mujeres aparecen como más completas, pero al mismo tiempo asumiendo menos riesgos. Sus obligaciones familiares, el hecho que "siempre apaña con los cabros chicos", las vuelve más prudentes. Estos atributos que dificultan la "aventura" de emprender, desde otra lectura serían favorables para una mujer, precisamente por el carácter de madre/cuidadora y de una "naturaleza" femenina no apta para el mundo del riesgo y la aventura. Ciertas cualidades desarrolladas en el espacio privado son volcadas hacia lo público, y resultan valoradas positivamente aun cuando en la práctica corresponden a actividades que funcionan o funcionaron durante mucho tiempo bajo otros códigos.

El sacrificio por el otro y la consciencia de un otro dependiente al cual proteger, cuidar y alimentar, llevan a la mujer a ser más operativa; mientras que el hombre -descuidando aparentemente esos aspectos y de manera más individualista- se enfoca en dirigir. Esto resulta coherente con la definición de emprendedor como "hombre de acción", ya que supone un tipo de "hombre" definido como agente enérgico, directivo, motor de la economía, que responde a ciertos atributos considerados tradicionalmente masculinos. Esto que resulta al menos paradojal, adquiere otro sentido cuando se trata de la toma de riesgos, ya que estos son calculados: si bien las mujeres no son "machos" sí serían aguerridas, valientes y fuertes para afrontar los costos asociados a esos riesgos.

\section{Algunas consideraciones finales}

El objeto de este trabajo era abordar la experiencia emprendedora de un grupo acotado de hombres y mujeres de distintas características y los significados que le otorgan a una actividad en constante expansión. Más allá de discutir sobre la gestión de los emprendimientos 
y su importancia en la economía, mediante este análisis queremos aportar a un debate crítico sobre cómo el emprendimiento, en tanto experiencia vital, moldea la subjetividad de quien emprende.

Si bien se trata de una muestra acotada y que puede presentar limitaciones al enfocarse en emprendedores de la Región Metropolitana, los relatos recogidos en este trabajo permiten profundizar en aspectos que, por lo general, se observan separadamente: los emprendimientos de mujeres y la situación de los emprendedores sin "distinción de género". En estos relatos se observa una gran similitud con los contenidos que se difunden en cursos, talleres, manuales, etc., aun entre quienes no han tenido acceso a capacitaciones, y que incorporan estos contenidos, así como las valoraciones referidas al emprendimiento. Se trata de un discurso que se hace presente en la vida cotidiana, que circula en los medios televisivos, en la prensa y en la internet, que se replica y reproduce a través de la naturalización del emprendimiento como una "opción", pero además mediante la reelaboración de ideas y valores preexistentes en nuestra sociedad. Esto es, el valor del esfuerzo y el sacrificio para enfrentar la vida y las dificultades económicas; la felicidad como posibilidad asociada al consumo, como autosatisfacción de las necesidades materiales y vehículo de las pasiones, así como la independencia económica como equivalente de libertad, al asumir que las condiciones del trabajo asalariado no se pueden modificar.

Respecto a la dimensión de género, el análisis muestra un énfasis en los roles y atributos tradicionales que revela el carácter masculino del emprendimiento: la toma de riesgos, el llamado a la acción, y la autosuficiencia como forma de desenvolverse en lo público. No obstante, los atributos femeninos pueden adaptarse: el sacrificio por los otros, la compatibilización entre el trabajo remunerado y la familia. Son las mujeres las llamadas a asumir los atributos masculinos para desenvolverse en un ámbito que también lo es -el económico- pero, al parecer, no ocurre lo mismo entre los varones, que no manifiestan la necesidad de compatibilizar sus actividades familiares con sus emprendimientos. $\mathrm{O}$ al menos no lo explicitan como una prioridad -que no es lo mismo que plantearlo como una posibilidad- en el presente o en el futuro, entre quienes no son los responsables exclusivos del cuidado de sus hijos o de personas dependientes.

Las mujeres se proyectan fundamentalmente en la subsistencia -varias tienen hijos solas-, mientras los hombres lo hacen en la prosecución de sus sueños y la búsqueda de independencia. Esto no significa que las mujeres entrevistadas no se planteen el emprendimiento como una posibilidad de concretar un sueño, sino que dicha concreción va asociada a la responsabilidad de un tercero, generalmente un hijo.

De este modo, pese a que en un primer nivel el emprendimiento se presenta como una actividad sin "marcas" de género -y es reconocida como tal por los entrevistados y entrevistadas- en un segundo nivel de reflexión puede llegar a articularse con ideas de género conservadoras y contribuir a perpetuar desigualdades entre hombres y mujeres, sobre todo entre quienes cuentan con menos recursos. No obstante, cabe tener en cuenta un elemento en común, aunque con distintas expresiones. En las experiencias de emprendimiento lo público y lo privado no aparecen como esferas separadas, ya que el sujeto debe hacer de sus pasiones y sueños más íntimos el soporte de su actividad laboral. El discurso emprendedor impregna así las identidades individuales, hombres y mujeres se apropian de estas ideas, inclusive con un propósito social pero cuyo éxito se traduce necesariamente en una ganancia económica, que puede ser su propia subsistencia material.

Así, en la elaboración de su experiencia como emprendedores se aprecia una tensión. Por un lado, el emprendimiento aparece como una elección libre y posible entre el trabajo dependiente y una actividad propia, una idea propia que se traduce en un producto o servicio. Por otro, en varios casos se advierte que la elección no es tal ni con un amplio margen de libertad, más bien resulta de una contingencia que obliga a desplegar todos los recursos 
disponibles, particularmente los personales, hasta dar forma a un negocio o la venta de un servicio al cual se denomina como emprendimiento. Y sobre el cual proyectan su existencia.

\section{Bibliografía}

Amorós, J. E. y Pizarro, O. (2007) GEM. Mujeres y actividad emprendedora Chile 2006-2007. Santiago: Ediciones Universidad del Desarrollo.

Bonan, C. y Guzmán, V. (2007). “Aportes de la teoría de género a la comprensión de las dinámicas sociales y los temas específicos de asociatividad y participación, identidad y poder", Santiago: CEM, Documento de trabajo, junio. Disponible en http: //www.cem.cl/pdf/aportes. pdf

Brega, C. (2016). "Empleo por cuenta propia y el mito del emprendimiento". DiarioUChile, 26 de octubre. Disponible en línea en: http: //radio.uchile.cl/2016/10/26/empleo-por-cuentapropia-y-el-mito-del-emprendimiento/ [Consultado: 30/04/2017]

Bröckling, U. (2015). El self emprendedor. Sociología de una forma de subjetivación. Santiago: Ediciones Universidad Alberto Hurtado.

Canales, M. (2006). Metodologías de investigación social: Introducción a los oficios. Santiago: LOM.

Carosio, A. (2004). "Las mujeres y la opción emprendedora: consideraciones sobre la gestión”. Revista Venezolana de Estudios de la Mujer, 9 (23): 79-112. Disponible en línea en: http: // saber.ucv.ve/ojs/index.php/rev_vem/article/view/2257

Carreño, C. (2013). "Hoy se celebra en Chile el primer Día Nacional del Emprendimiento". Pulso Social, 29 de abril. Disponible en línea en: http: //pulsosocial.com/2013/04/29/hoy-secelebra-en-chile-el-primer-dia-nacional-del-emprendimiento/ [Consultado: 25/11/2015]

CORFO (2012). Emprendimiento escolar: habilidades y competencias. Informe resumen de línea base: programa de apoyo al entorno de emprendimiento escolar año 2012. Gerencia de innovación -Unidad de monitoreo y evaluación. Gerencia de estrategia y estudio. Disponible en línea: http: //repositoriodigital.corfo.cl/bitstream/handle/11373/10098/83empren dimientoescolarhabilidadesycompetencias.pdf?sequence $=1$

CORFO (2014). Emprendimiento en Chile: hacia un modelo de segmentación.

Disponible en línea en: http: //repositoriodigital.corfo.cl/bitstream/handle/11373/9871/EMPRENDIMIENTO\%20EN\%20CHILE\%20hacia\%20un\%20modelo\%20de\%20segmentacion. pdf? sequence $=3$

Foucault, M. (2007). Nacimiento de la biopolítica. Curso en el Collège de France (1978-1979), Buenos Aires: Fondo de Cultura Económica.

Freeman, C. (2014). Entrepreneurial Selves. Neoliberal respectability and the making of a Caribbean middle class. Duke University Press / Durham and London.

Garrido P., F. (2016). “Trabajadores por cuenta propia: quiénes son los que soportan el bajo desempleo en Chile". La Segunda, 31 de marzo. Disponible en: http: //impresa.lasegunda. com/2016/03/31/A/5Q2TDL4U/O42TE7CE [Consultado: 22/04/2016]

Godoy, C. G. (2016). "No somos feministas". Género, igualdad y neoliberalismo en Chile. Revista Estudos Feministas, 24(3), 871-889. https: //dx.doi.org/10.1590/1806-9584-2016v24n3p871

Guber, R. (2001). La etnografía: método, campo y reflexividad. Buenos Aires: Norma.

Hernández, R., Fernández, C. y Baptista, P. (2006). Metodología de la investigación. México D. F.: Mc Graw Hill / Interamericana.

Herrera Ronco, J. (2016). Impacto emprendedor. La fuerza que mueve al mundo. Santiago: Ediciones UC.

Innovación.cl (2013). "9 mitos sobre emprender que vale la pena aclarar”. Disponible en: http: // www.innovacion.c1/2013/01/9-mitos-sobre-emprender-que-vale-la-pena-aclarar/ [Consultado: 25/11/2015]

Ministerio de Economía, Fomento y Turismo (2016). "Informe de resultados: El microemprendedor en Chile. Cuarta Encuesta de Microemprendimiento". Newsletter, Vol. 29, febrero. Disponible en: http: //www.economia.gob.cl/wp-content/uploads/2016/02/Informe-de-resultados-EME4-el-microemprendedor-en-Chile.pdf [Consultado: 15/06/2016]

Nelson, J. (1995). “Feminismo y economía”. Journal of Economic Perspectives, Vol. 9 N² 2. Ameri- 
can Economic Association; distribuido por la autora según las políticas del Journal of Economic Perspectives. Traducido por J. Nelson y H. Ocampo Delahay. Disponible en: http: // www.ase.tufts.edu/gdae/about_us/cv/nelson_papers/nelson_feminismo_y_economia.pdf

Ortiz, C., Duque, Y. y Camargo, D. (2008). "Una revisión a la investigación en emprendimiento femenino". Revista Facultad de Ciencias Económicas, Universidad Militar Nueva Granada, XVI (1), 85-104. Disponible en: http: //www.scielo.org.co/pdf/rfce/v16n1/v16n1a07.pdf

Pfeilstetter, R. (2011). "El emprendedor. Una reflexión crítica sobre usos y significados actuales de un concepto". Gazeta de Antropología, N. ${ }^{\circ} 27$ /1, 2011, Artículo 16. Disponible en línea en: http: //hdl.handle.net/10481/15684

Santander-Astorga, P., Fernández-Robin, C, y Yáñez-Martínez, D. (2016). "Motivaciones y condicionantes contextuales en el emprendimiento liderado por mujeres chilenas". Revista de Ciencias Sociales (Ve), vol. XXII, núm. 2, Universidad del Zulia. Disponible en: http: // www.redalyc.org/articulo.oa?id=28049145006

Soteras, J. (2017). "Robert Kiyosaki: "Donald Trump es mi padre rico". El Mundo, 25 de febrero. Disponible en línea en: http: //www.elmundo.es/economia/2017/02/25/58a6fdd4268e3e1 74b8b4695.html [Consultado: 25/03/2017]

Tapia, P. (2016): "Vender sopaipillas en la esquina también es emprender. Me agrede que los lleven presos". La Segunda, 21 de marzo. Disponible en línea en: http: //impresa.lasegunda. com/2016/03/21/A/1S2T6EDS [Consultado: 31/03/2016]

Valdivieso, M. (2009). “Globalización, género y patrón de poder”, en Girón, A. (coord.). Género y globalización. Buenos Aires: CLACSO.

Valenzuela, M. E. (ed.) (2005). ¿Nuevo sendero para las mujeres? Microempresa y género en América Latina en el umbral del siglo XXI. Santiago: LOM/CEM.

Valenzuela, M. E. y Venegas, S. (2001). Mitos y realidades de la microempresa en Chile: un análisis de género. Santiago: CEM

\section{Páginas web consultadas}

CORFO Emprendimiento

https: //www.corfo.cl/sites/cpp/\%20emprendimiento?resolvetemplatefordevice=true.

Academia de la Felicidad Curso Emprendedores con Propósito

http: //www.academiafelicidad.org/curso-emprendedores-e-learning/

ASECH Directorio

https: //www.asech.cl/nosotros/directorio/ 